\title{
Strong Convergence Theorem for Bregman Strongly Nonexpansive Mappings and Equilibrium Problems in Reflexive Banach Spaces
}

\author{
Jinhua Zhu, ${ }^{1}$ Shih-sen Chang, ${ }^{2}$ and Min Liu' ${ }^{1}$ \\ ${ }^{1}$ Department of Mathematics, Yibin University, Yibin, Sichuan 644007, China \\ ${ }^{2}$ College of Statistics and Mathematics, Yunnan University of Finance and Economics, Kunming, Yunnan 650221, China \\ Correspondence should be addressed to Shih-sen Chang; changss@yahoo.cn
}

Received 30 April 2013; Accepted 10 June 2013

Academic Editor: Wei-Shih Du

Copyright (C) 2013 Jinhua Zhu et al. This is an open access article distributed under the Creative Commons Attribution License, which permits unrestricted use, distribution, and reproduction in any medium, provided the original work is properly cited.

By using a new hybrid method, a strong convergence theorem for finding a common element of the set of solutions of an equilibrium problem and the set of fixed points of Bregman strongly nonexpansive mappings in a reflexive Banach space is proved.

\section{Introduction}

Throughout this paper, we denote by $\mathbb{R}$ and $\mathbb{R}^{+}$the set of all real numbers and all nonnegative real numbers, respectively. We also assume that $E$ is a real reflexive Banach space, $E^{*}$ is the dual space of $E, C$ is a nonempty closed convex subset of $E$, and $\langle\cdot, \cdot\rangle$ is the pairing between $E$ and $E^{*}$. Let $\Theta$ be a bifunction from $C \times C \rightarrow \mathbb{R}$. The equilibrium problem is to find

$$
x^{*} \in C \text { such that } \Theta\left(x^{*}, y\right) \geq 0, \quad \forall y \in C .
$$

The set of such solutions $x^{*}$ is denoted by $\operatorname{EP}(\Theta)$.

Recall that a mapping $T: C \rightarrow C$ is said to be nonexpansive, if

$$
\|T x-T y\| \leq\|x-y\|, \quad \forall x, y \in C .
$$

We denote by $F(T)$ the set of fixed points of $T$.

Numerous problems in physics, optimization, and economics reduce to find a solution of the equilibrium problem. Some methods have been proposed to solve the equilibrium problem in a Hilbert spaces; see, for instance, Blum and Oettli [1], Combettes and Hirstoaga [2], and Moudafi [3]. Recently, Tada and Takahashi $[4,5]$ and S. Takahashi and W. Takahashi [6] obtained weak and strong convergence theorems for finding a common element of the set of solutions of an equilibrium problem and the set of fixed points of a nonexpansive mapping in a Hilbert space. In particular, Tada and Takahashi [4] established a strong convergence theorem for finding a common element of two sets by using the hybrid method introduced by Nakajo and Takahashi [7]. The authors also proved such a strong convergence theorem in a uniformly convex and uniformly smooth Banach space.

In this paper, motivated by Takahashi et al. [8], we prove a strong convergence theorem for finding a common element of the set of solutions of an equilibrium problem and the set of fixed points of a Bregman strongly nonexpansive mapping in a real reflexive Banach space by using the shrinking projection method. Using this theorem, we obtain two new strong convergence results for finding a solution of an equilibrium problem and a fixed point of Bregman strongly nonexpansive mappings in a real reflexive Banach space.

\section{Preliminaries and Lemmas}

In the sequel, we begin by recalling some preliminaries and lemmas which will be used in the proof.

Let $E$ be a real reflexive Banach space with the norm $\|\cdot\|$ and $E^{*}$ the dual space of $E$. Throughout this paper, $f: E \rightarrow(-\infty,+\infty]$ is a proper, lower semicontinuous, and convex function. We denote by $\operatorname{dom} f$ the domain of $f$, that is, the set $\{x \in E: f(x)<+\infty\}$. 
Let $x \in \operatorname{int} \operatorname{dom} f$. The subdifferential of $f$ at $x$ is the convex set defined by

$$
\begin{aligned}
\partial f(x)=\left\{x^{*} \in E^{*}:\right. & f(x)+\left\langle x^{*}, y-x\right\rangle \\
& \leq f(y), \forall y \in E\},
\end{aligned}
$$

where the Fenchel conjugate of $f$ is the function $f^{*}: E^{*} \rightarrow$ $(-\infty,+\infty]$ defined by

$$
f^{*}\left(x^{*}\right)=\sup \left\{\left\langle x^{*}, x\right\rangle-f(x): x \in E\right\} .
$$

We know that the Young-Fenchel inequality holds:

$$
\left\langle x^{*}, x\right\rangle \leq f(x)+f^{*}\left(x^{*}\right), \quad \forall x \in E, x^{*} \in E^{*} .
$$

A function $f$ on $E$ is coercive [9] if the sublevel set of $f$ is bounded; equivalently,

$$
\lim _{\|x\| \rightarrow+\infty} f(x)=+\infty .
$$

A function $f$ on $E$ is said to be strongly coercive [10] if

$$
\lim _{\|x\| \rightarrow+\infty} \frac{f(x)}{\|x\|}=+\infty \text {. }
$$

For any $x \in \operatorname{int} \operatorname{dom} f$ and $y \in E$, the right-hand derivative of $f$ at $x$ in the direction $y$ is defined by

$$
f^{\circ}(x, y):=\lim _{t \rightarrow 0^{+}} \frac{f(x+t y)-f(x)}{t} .
$$

The function $f$ is said to be Gâteaux differentiable at $x$ if $\lim _{t \rightarrow 0^{+}}((f(x+t y)-f(x)) / t)$ exists for any $y$. In this case, $f^{\circ}(x, y)$ coincides with $\nabla f(x)$, the value of the gradient $\nabla f$ of $f$ at $x$. The function $f$ is said to be Gâteaux differentiable if it is Gâteaux differentiable for any $x \in \operatorname{int} \operatorname{dom} f$. The function $f$ is said to be Fréchet differentiable at $x$ if this limit is attained uniformly in $\|y\|=1$. Finally, $f$ is said to be uniformly Fréchet differentiable on a subset $C$ of $E$ if the limit is attained uniformly for $x \in C$ and $\|y\|=1$. It is known that if $f$ is Gâteaux differentiable (resp., Fréchet differentiable) on int $\operatorname{dom} f$, then $f$ is continuous and its Gâteaux derivative $\nabla f$ is norm-to-weak ${ }^{*}$ continuous (resp., continuous) on int dom $f$ (see also [11, 12]). We will need the following result.

Lemma 1 (see [13]). If $f: E \rightarrow \mathbb{R}$ is uniformly Fréchet differentiable and bounded on bounded subsets of $E$, then $\nabla f$ is uniformly continuous on bounded subsets of $E$ from the strong topology of $E$ to the strong topology of $E^{*}$.

Definition 2 (see [14]). The function $f$ is said to be

(i) essentially smooth, if $\partial f$ is both locally bounded and single valued on its domain,

(ii) essentially strictly convex, if $(\partial f)^{-1}$ is locally bounded on its domain and $f$ is strictly convex on every convex subset of dom $\partial f$,

(iii) Legendre if it is both essentially smooth and essentially strictly convex.
Remark 3. Let $E$ be a reflexive Banach space. Then we have the following.

(i) $f$ is essentially smooth if and only if $f^{*}$ is essentially strictly convex (see [14, Theorem 5.4]).

(ii) $(\partial f)^{-1}=\partial f^{*}($ see $[12])$.

(iii) $f$ is Legendre if and only if $f^{*}$ is Legendre (see [14, Corollary 5.5]).

(iv) If $f$ is Legendre, then $\nabla f$ is a bijection satisfying $\nabla f=\left(\nabla f^{*}\right)^{-1}, \operatorname{ran} \nabla f=\operatorname{dom} \nabla f^{*}=\operatorname{int} \operatorname{dom} f^{*}$, and $\operatorname{ran} \nabla f^{*}=\operatorname{dom} \nabla f=\operatorname{int} \operatorname{dom} f$ (see [14, Theorem $5.10])$.

Examples of Legendre functions were given in [14, 15]. One important and interesting Legendre function is $(1 / p)\|\cdot\|^{p}(1<p<\infty)$ when $E$ is a smooth and strictly convex Banach space. In this case, the gradient $\nabla f$ of $f$ is coincident with the generalized duality mapping of $E$; that is, $\nabla f=J_{p}(1<p<\infty)$. In particular, $\nabla f=I$ the identity mapping in Hilbert spaces. In the rest of this paper, we always assume that $f: E \rightarrow(-\infty,+\infty]$ is Legendre.

Let $f: E \rightarrow(-\infty,+\infty]$ be a convex and Gâteaux differentiable function. The function $D_{f}: \operatorname{dom} f \times \operatorname{int} \operatorname{dom} f \rightarrow$ $[0,+\infty)$ defined as

$$
D_{f}(y, x):=f(y)-f(x)-\langle\nabla f(x), y-x\rangle
$$

is called the Bregman distance with respect to $f$ [16].

Recall that the Bregman projection [17] of $x \in \operatorname{int} \operatorname{dom} f$ onto the nonempty closed and convex set $C \subset \operatorname{dom} f$ is the necessarily unique vector $P_{C}^{f}(x) \in C$ satisfying

$$
D_{f}\left(P_{C}^{f}(x), x\right)=\inf \left\{D_{f}(y, x): y \in C\right\} .
$$

Concerning the Bregman projection, the following are well known.

Lemma 4 (see [18]). Let $C$ be a nonempty, closed, and convex subset of a reflexive Banach space $E$. Let $f: E \rightarrow \mathbb{R}$ be a Gâteaux differentiable and totally convex function and let $x \in$ E. Then
(a) $z=P_{C}^{f}(x)$ if and only if $\langle\nabla f(x)-\nabla f(z), y-z\rangle \leq 0$, for all $y \in C$.

(b)

$$
\begin{array}{r}
D_{f}\left(y, P_{C}^{f}(x)\right)+D_{f}\left(P_{C}^{f}(x), x\right) \leq D_{f}(y, x), \\
\forall x \in E, \quad y \in C .
\end{array}
$$

Let $f: E \rightarrow(-\infty,+\infty]$ be a convex and Gâteaux differentiable function. The modulus of total convexity of $f$ at $x \in \operatorname{int} \operatorname{dom} f$ is the function $v_{f}(x, \cdot):[0,+\infty) \rightarrow[0,+\infty]$ defined by

$$
v_{f}(x, t):=\inf \left\{D_{f}(y, x): y \in \operatorname{dom} f,\|y-x\|=t\right\} .
$$

The function $f$ is called totally convex at $x$ if $v_{f}(x, t)>0$ whenever $t>0$. The function $f$ is called totally convex if 
it is totally convex at any point $x \in \operatorname{int} \operatorname{dom} f$ and is said to be totally convex on bounded sets if $\nu_{f}(B, t)>0$ for any nonempty bounded subset $B$ of $E$ and $t>0$, where the modulus of total convexity of the function $f$ on the set $B$ is the function $v_{f}:$ int $\operatorname{dom} f \times[0,+\infty) \rightarrow[0,+\infty]$ defined by

$$
v_{f}(B, t):=\inf \left\{v_{f}(x, t): x \in B \cap \operatorname{dom} f\right\} .
$$

The next lemma will be useful in the proof of our main results.

Lemma 5 (see [19]). If $x \in \operatorname{dom} f$, then the following statements are equivalent.

(i) The function $f$ is totally convex at $x$.

(ii) For any sequence $\left\{y_{n}\right\} \subset \operatorname{dom} f$,

$$
\lim _{n \rightarrow+\infty} D_{f}\left(y_{n}, x\right)=0 \Longrightarrow \lim _{n \rightarrow+\infty}\left\|y_{n}-x\right\|=0 \text {. }
$$

Recall that the function $f$ is called sequentially consistent [18] if, for any two sequences $\left\{x_{n}\right\}$ and $\left\{y_{n}\right\}$ in $E$ such that the first one is bounded,

$$
\lim _{n \rightarrow+\infty} D_{f}\left(y_{n}, x_{n}\right)=0 \Longrightarrow \lim _{n \rightarrow+\infty}\left\|y_{n}-x_{n}\right\|=0 .
$$

Lemma 6 (see [20]). The function $f$ is totally convex on bounded sets if and only if the function $f$ is sequentially consistent.

Lemma 7 (see [21]). Let $f: E \rightarrow \mathbb{R}$ be a Gâteaux differentiable and totally convex function. If $x_{0} \in E$ and the sequence $\left\{D_{f}\left(x_{n}, x_{0}\right)\right\}$ is bounded, then the sequence $\left\{x_{n}\right\}$ is bounded too.

Lemma 8 (see [21]). Let $f: E \rightarrow \mathbb{R}$ be a Gâteaux differentiable and totally convex function, $x_{0} \in E$, and let $C$ be a nonempty, closed, and convex subset of E. Suppose that the sequence $\left\{x_{n}\right\}$ is bounded and any weak subsequential limit of $\left\{x_{n}\right\}$ belongs to $C$. If $D_{f}\left(x_{n}, x_{0}\right) \leq D_{f}\left(P_{C}^{f} x_{0}, x_{0}\right)$ for any $n \in \mathbb{N}$, then $\left\{x_{n}\right\}$ converges strongly to $P_{C}^{f} x_{0}$.

Let $C$ be a convex subset of int $\operatorname{dom} f$ and let $T$ be a selfmapping of $C$. A point $p \in C$ is called an asymptotic fixed point of $T$ (see $[22,23]$ ) if $C$ contains a sequence $\left\{x_{n}\right\}$ which converges weakly to $p$ such that $\lim _{n \rightarrow \infty}\left\|x_{n}-T x_{n}\right\|=0$. We denote by $\widehat{F}(T)$ the set of asymptotic fixed points of $T$.

Definition 9. A mapping $T$ with a nonempty asymptotic fixed point set $\widehat{F}(T)$ is said to be

(i) Bregman strongly nonexpansive (see $[24,25])$ with respect to $\widehat{F}(T)$ if

$D_{f}(p, T x) \leq D_{f}(p, x), \quad \forall x \in C, p \in \widehat{F}(T)$,

and if, whenever $\left\{x_{n}\right\} \subset C$ is bounded, $p \in \widehat{F}(T)$ and

$$
\lim _{n \rightarrow \infty}\left(D_{f}\left(p, x_{n}\right)-D_{f}\left(p, T x_{n}\right)\right)=0,
$$

it follows that

$$
\lim _{n \rightarrow \infty} D_{f}\left(x_{n}, T x_{n}\right)=0 .
$$

(ii) Bregman firmly nonexpansive [26] if, for all $x, y \in C$,

$$
\begin{aligned}
& \langle\nabla f(T x)-\nabla f(T y), T x-T y\rangle \\
& \quad \leq\langle\nabla f(x)-\nabla f(y), T x-T y\rangle
\end{aligned}
$$

or, equivalently,

$$
\begin{aligned}
& D_{f}(T x, T y)+D_{f}(T y, T x)+D_{f}(T x, x)+D_{f}(T y, y) \\
& \leq D_{f}(T x, y)+D_{f}(T y, x) .
\end{aligned}
$$

The existence and approximation of Bregman firmly nonexpansive mappings were studied in [26]. It is also known that if $T$ is Bregman firmly nonexpansive and $f$ is Legendre function which is bounded, uniformly Fréchet differentiable and totally convex on bounded subsets of $E$, then $F(T)=$ $\widehat{F}(T)$ and $F(T)$ is closed and convex (see [26]). It also follows that every Bregman firmly nonexpansive mapping is Bregman strongly nonexpansive with respect to $F(T)=\widehat{F}(T)$.

Lemma 10 (see [27]). Let $E$ be a real reflexive Banach space and $f: E \rightarrow(-\infty,+\infty]$ a proper lower semicontinuous function; then $f^{*}: E^{*} \rightarrow(-\infty,+\infty]$ is a proper weak ${ }^{*}$ lower semicontinuous and convex function. Thus, for all $z \in E$, we have

$$
D_{f}\left(z, \nabla f^{*}\left(\sum_{i=1}^{N} t_{i} \nabla f\left(x_{i}\right)\right)\right) \leq \sum_{i=1}^{N} t_{i} D_{f}\left(z, x_{i}\right) \text {. }
$$

In order to solve the equilibrium problem, let us assume that a bifunction $\Theta: C \times C \rightarrow \mathbb{R}$ satisfies the following conditions [28]:

$\left(A_{1}\right) \Theta(x, x)=0$, for all $x \in C$.

$\left(A_{2}\right) \Theta$ is monotone; that is, $\Theta(x, y)+\Theta(y, x) \leq 0$, for all $x, y \in C$.

$\left(A_{3}\right) \lim \sup _{t \downarrow 0} \Theta(x+t(z-x), y) \leq \Theta(x, y)$ for all $x, z, y \in$ C.

$\left(A_{4}\right)$ The function $y \mapsto \Theta(x, y)$ is convex and lower semicontinuous.

The resolvent of a bifunction $\Theta[29]$ is the operator $\operatorname{Res}_{\Theta}^{f}$ : $E \rightarrow 2^{C}$ defined by

$$
\begin{gathered}
\operatorname{Res}_{\Theta}^{f}(x)=\{z \in C: \Theta(z, y)+\langle\nabla f(z)-\nabla f(x), y-z\rangle \\
\geq 0, \forall y \in C\} .
\end{gathered}
$$

From Lemma 1 in [24], if $f: E \rightarrow(-\infty,+\infty]$ is a strongly coercive and Gâteaux differentiable function and $\Theta$ satisfies conditions $\left(A_{1}-A_{4}\right)$, then $\operatorname{dom}\left(\operatorname{Res}_{\Theta}^{f}\right)=E$. We also know the following lemma which gives us some characterizations of the resolvent $\operatorname{Res}_{\Theta}^{f}$. 
Lemma 11 (see [24]). Let $E$ be a real reflexive Banach space and $C$ a nonempty closed convex subset of $E$. Let $f: E \rightarrow$ $(-\infty,+\infty]$ be a Legendre function. If the bifunction $\Theta: C \times$ $C \rightarrow \mathbb{R}$ satisfies the conditions $\left(A_{1}\right)-\left(A_{4}\right)$, then the followings hold:

(i) $\operatorname{Res}_{\Theta}^{f}$ is single-valued;

(ii) $\operatorname{Res}_{\Theta}^{f}$ is a Bregman firmly nonexpansive operator;

(iii) $F\left(\operatorname{Res}_{\Theta}^{f}\right)=E P(\Theta)$;

(iv) $E P(\Theta)$ is a closed and convex subset of $C$;

(v) for all $x \in E$ and for all $q \in F\left(\operatorname{Res}_{\Theta}^{f}\right)$, we have

$$
D_{f}\left(q, \operatorname{Res}_{\Theta}^{f}(x)\right)+D_{f}\left(\operatorname{Res}_{\Theta}^{f}(x), x\right) \leq D_{f}(q, x) .
$$

\section{Strong Convergence Theorem}

In this section, we proved a strong convergence theorem for finding a common element of the set of solutions of an equilibrium problem and a fixed point of Bregman strongly nonexpansive mapping in a real reflexive Banach space by using the shrinking projection method.

Theorem 12. Let $C$ be a nonempty, closed, and convex subset of a real reflexive Banach space $E$ and $f: E \rightarrow \mathbb{R}$ a strongly coercive Legendre function which is bounded, uniformly Fréchet differentiable, and totally convex on bounded subsets of E. Let $g$ be a bifunction from $C \times C$ to $\mathbb{R}$ satisfying $\left(A_{1}\right)-\left(A_{4}\right)$ and let $T$ be a Bregman strongly nonexpansive mapping from $C$ into itself such that $F(T)=\widehat{F}(T)$ and $G=F(T) \cap E P(g) \neq \emptyset$. Let $\left\{x_{n}\right\}$ be a sequence generated by $x_{0}=x \in C, C_{0}=C$ and

$$
\begin{aligned}
& y_{n}=\nabla f^{*}\left(\alpha_{n} \nabla f\left(x_{n}\right)+\left(1-\alpha_{n}\right) \nabla f\left(T x_{n}\right)\right), \\
& u_{n} \in C \text { such that } \\
& g\left(u_{n}, y\right)+\left\langle\nabla f\left(u_{n}\right)-\nabla f\left(y_{n}\right), y-u_{n}\right\rangle \geq 0, \\
& \forall y \in C, \\
& C_{n+1}=\left\{z \in C_{n}: D_{f}\left(z, u_{n}\right) \leq D_{f}\left(z, x_{n}\right)\right\}, \\
& x_{n+1}=P_{C_{n+1} x}^{f}
\end{aligned}
$$

for every $n \in \mathbb{N} \cup\{0\}$, where $\left\{\alpha_{n}\right\} \subset[0,1]$ satisfies $\liminf _{n \rightarrow \infty}\left(1-\alpha_{n}\right)>0$. Then, $\left\{x_{n}\right\}$ converges strongly to $P_{F(T) \cap E P(g)}^{f} x$, where $P_{F(T) \cap E P(g)}^{f}$ is the Bregman projection of $E$ onto $F(T) \cap E P(g)$.

Proof. We divide the proof of Theorem 12 into five steps.

(I) We first prove that $G$ and $C_{n}$ both are closed and convex subset of $C$ for all $n \geq 0$. In fact, it follows from Lemma 11 and by Reich and Sabach [26] that $\operatorname{EP}(g)$ and $F(T)$ both are closed and convex. Therefore, $G$ is a closed and convex subset in $C$. Furthermore, it is obvious that $C_{0}=C$ is closed and convex. Suppose that $C_{n}$ is closed and convex for some $n \geq 1$. Since the inequality $D_{f}\left(z, u_{n}\right) \leq D_{f}\left(z, x_{n}\right)$ is equivalent to

$$
\left\langle\nabla f\left(x_{n}\right), z-x_{n}\right\rangle-\left\langle\nabla f\left(u_{n}\right), z-u_{n}\right\rangle \leq f\left(u_{n}\right)-f\left(x_{n}\right) .
$$

Therefore, we have

$$
\begin{aligned}
C_{n+1}=\left\{z \in C_{n}\right. & :\left\langle\nabla f\left(x_{n}\right), z-x_{n}\right\rangle-\left\langle\nabla f\left(u_{n}\right), z-u_{n}\right\rangle \\
\leq & \left.f\left(u_{n}\right)-f\left(x_{n}\right)\right\} .
\end{aligned}
$$

This implies that $C_{n+1}$ is closed and convex. The desired conclusions are proved. These in turn show that $P_{F(T) \cap \mathrm{EP}(g)}^{f} x$ and $P_{C_{n}}^{f} x$ are well defined.

(II) we prove that $G:=F(T) \cap \operatorname{EP}(g) \subset C_{n}$ for all $n \geq 0$.

Indeed, it is obvious that $G=F(T) \cap \operatorname{EP}(g) \subset C_{0}=C$. Suppose that $G \subset C_{n}$ for some $n \in \mathbb{N}$. Let $u \in G \subset C_{n}$; since $u_{n}=\operatorname{Res}_{g}^{f}\left(y_{n}\right)$, by Lemma 11 and (21), we have

$$
\begin{aligned}
D_{f}\left(u, u_{n}\right) & =D_{f}\left(u, \operatorname{Res}_{g}^{f} y_{n}\right) \leq D_{f}\left(u, y_{n}\right) \\
& =D_{f}\left(u, \nabla f^{*}\left(\alpha_{n} \nabla f\left(x_{n}\right)+\left(1-\alpha_{n}\right) \nabla f\left(T x_{n}\right)\right)\right) \\
& \leq \alpha_{n} D_{f}\left(u, x_{n}\right)+\left(1-\alpha_{n}\right) D_{f}\left(u, T x_{n}\right) \\
& \leq \alpha_{n} D_{f}\left(u, x_{n}\right)+\left(1-\alpha_{n}\right) D_{f}\left(u, x_{n}\right) \\
& =D_{f}\left(u, x_{n}\right) .
\end{aligned}
$$

Hence, we have $u \in C_{n+1}$. This implies that

$$
F(T) \cap \operatorname{EP}(g) \subset C_{n}, \quad \forall n \in \mathbb{N} \cup\{0\} .
$$

So, $\left\{x_{n}\right\}$ is well defined.

(III) We prove that $\left\{x_{n}\right\}$ is a bounded sequence in $C$.

By the definition of $C_{n}$, we have $x_{n}=P_{C_{n}}^{f} x$ for all $n \geq 0$. It follows from Lemma 4(b) that

$$
\begin{aligned}
D_{f}\left(x_{n}, x\right) & =D_{f}\left(P_{C_{n}}^{f} x, x\right) \leq D_{f}(u, x)-D_{f}\left(u, P_{C_{n}}^{f} x\right) \\
& \leq D_{f}(u, x), \quad \forall n \geq 0, u \in G .
\end{aligned}
$$

This implies that $\left\{D_{f}\left(x_{n}, x\right)\right\}$ is bounded. By Lemma 7, $\left\{x_{n}\right\}$ is bounded. Since $f: E \rightarrow \mathbb{R}$ is uniformly Fréchet differentiable and bounded on bounded subsets of $E$, by Lemma $1 \nabla f$ is uniformly continuous and bounded on bounded subsets of $E$. This implies that $\left\{\nabla f\left(x_{n}\right)\right\}$ is bounded.

(IV) Now we proved that $\lim _{n \rightarrow \infty}\left\|x_{n}-T x_{n}\right\|=0$.

From $x_{n+1} \in C_{n+1} \subset C_{n}$ and $x_{n}=P_{C_{n}}^{f} x$, we have

$$
D_{f}\left(x_{n}, x\right) \leq D_{f}\left(x_{n+1}, x\right), \quad \forall n \in \mathbb{N} \cup\{0\} .
$$

Thus, $\left\{D_{f}\left(x_{n}, x\right)\right\}$ is nondecreasing. So, the limit of $\left\{D_{f}\left(x_{n}\right.\right.$, $x)$ \} exists. Since $D_{f}\left(x_{n+1}, x_{n}\right)=D_{f}\left(x_{n+1}, P_{C_{n}}^{f} x\right) \leq D_{f}\left(x_{n+1}\right.$, $x)-D_{f}\left(P_{C_{n}}^{f} x, x\right)=D_{f}\left(x_{n+1}, x\right)-D_{f}\left(x_{n}, x\right)$ for all $n \geq 0$, we 
have $\lim _{n \rightarrow \infty} D_{f}\left(x_{n+1}, x_{n}\right)=0$. From $x_{n+1}=P_{C_{n+1}}^{f} x \in C_{n+1}$, we have

$$
D_{f}\left(x_{n+1}, u_{n}\right) \leq D_{f}\left(x_{n+1}, x_{n}\right), \quad \forall n \in \mathbb{N} \cup\{0\} .
$$

Therefore, we have

$$
\lim _{n \rightarrow \infty} D_{f}\left(x_{n+1}, u_{n}\right)=0 .
$$

From Lemma 5, we have

$$
\lim _{n \rightarrow \infty}\left\|x_{n+1}-x_{n}\right\|=\lim _{n \rightarrow \infty}\left\|x_{n+1}-u_{n}\right\|=0 .
$$

So, we have

$$
\lim _{n \rightarrow \infty}\left\|x_{n}-u_{n}\right\|=0 .
$$

This means that the sequence $\left\{u_{n}\right\}$ is bounded. Since $f$ is uniformly Fréchet differentiable, it follows from Lemma 1 that $\nabla f$ is uniformly continuous. Therefore, we have

$$
\lim _{n \rightarrow \infty}\left\|\nabla f\left(x_{n}\right)-\nabla f\left(u_{n}\right)\right\|=0 .
$$

Since $f$ is uniformly Fréchet differentiable on bounded subsets of $E$, then $f$ is uniformly continuous on bounded subsets of $E$ (see [30, Theorem 1.8]). It follows that

$$
\lim _{n \rightarrow \infty}\left|f\left(x_{n}\right)-f\left(u_{n}\right)\right|=0 .
$$

From the definition of the Bregman distance, we obtain that

$$
\begin{aligned}
& D_{f}\left(u, x_{n}\right)-D_{f}\left(u, u_{n}\right) \\
&= {\left[f(u)-f\left(x_{n}\right)-\left\langle\nabla f\left(x_{n}\right), u-x_{n}\right\rangle\right] } \\
&-\left[f(u)-f\left(u_{n}\right)-\left\langle\nabla f\left(u_{n}\right), u-u_{n}\right\rangle\right] \\
&=\left(f\left(u_{n}\right)-f\left(x_{n}\right)\right)+\left\langle\nabla f\left(u_{n}\right)-\nabla f\left(x_{n}\right), u-u_{n}\right\rangle \\
&+\left\langle\nabla f\left(x_{n}\right), x_{n}-u_{n}\right\rangle
\end{aligned}
$$

for any $u \in G$.

It follows from (34)-(37) that

$$
\lim _{n \rightarrow \infty}\left(D_{f}\left(u, x_{n}\right)-D_{f}\left(u, u_{n}\right)\right)=0 .
$$

On the other hand, from $u_{n}=\operatorname{Res}_{g}^{f} y_{n}$ and Lemma 11(v), for any $u \in G$ we have that

$$
\begin{aligned}
D_{f}\left(u_{n}, y_{n}\right) & =D_{f}\left(\operatorname{Res}_{g}^{f} y_{n}, y_{n}\right) \\
& \leq D_{f}\left(u, y_{n}\right)-D_{f}\left(u, \operatorname{Res}_{g}^{f} y_{n}\right) \\
& \leq D_{f}\left(u, x_{n}\right)-D_{f}\left(u, \operatorname{Res}_{g}^{f} y_{n}\right) \\
& =D_{f}\left(u, x_{n}\right)-D_{f}\left(u, u_{n}\right) .
\end{aligned}
$$

So, we have from (38) that

$$
\lim _{n \rightarrow \infty} D_{f}\left(u_{n}, y_{n}\right)=0 .
$$

From Lemma 5, we have

$$
\lim _{n \rightarrow \infty}\left\|u_{n}-y_{n}\right\|=0 .
$$

So, from (34) and (41),we have

$$
\lim _{n \rightarrow \infty}\left\|x_{n}-y_{n}\right\|=0 \text {. }
$$

This means that the sequence $\left\{y_{n}\right\}$ is bounded. Since $f$ is uniformly Fréchet differentiable, it follows from Lemma 1 that

$$
\lim _{n \rightarrow \infty}\left\|\nabla f\left(x_{n}\right)-\nabla f\left(y_{n}\right)\right\|=0
$$

Since $f$ is uniformly Fréchet differentiable on bounded subsets of $E$, then $f$ is uniformly continuous on bounded subsets of $E$ (see [30]). It follows that

$$
\lim _{n \rightarrow \infty}\left|f\left(x_{n}\right)-f\left(y_{n}\right)\right|=0 .
$$

From the definition of the Bregman distance, we obtain that

$$
\begin{aligned}
D_{f}\left(u, y_{n}\right)-D_{f}\left(u, x_{n}\right) \\
=\left[f(u)-f\left(y_{n}\right)-\left\langle\nabla f\left(y_{n}\right), u-y_{n}\right\rangle\right] \\
\quad-\left[f(u)-f\left(x_{n}\right)-\left\langle\nabla f\left(x_{n}\right), u-x_{n}\right\rangle\right] \\
=\left(f\left(x_{n}\right)-f\left(y_{n}\right)\right)-\left\langle\nabla f\left(y_{n}\right)-\nabla f\left(x_{n}\right), u-y_{n}\right\rangle \\
\quad+\left\langle\nabla f\left(x_{n}\right), y_{n}-x_{n}\right\rangle
\end{aligned}
$$

for any $u \in G$.

It follows from (42) to (45) that

$$
\lim _{n \rightarrow \infty}\left(D_{f}\left(u, y_{n}\right)-D_{f}\left(u, x_{n}\right)\right)=0 .
$$

On the other hand, for any $u \in G$ we have

$$
\begin{aligned}
D_{f}\left(u, y_{n}\right)-D_{f}\left(u, x_{n}\right) \\
=D_{f}\left(u, \nabla f^{*}\left(\alpha_{n} \nabla f\left(x_{n}\right)+\left(1-\alpha_{n}\right) \nabla f\left(T x_{n}\right)\right)\right) \\
\quad-D_{f}\left(u, x_{n}\right) \\
\leq \alpha_{n} D_{f}\left(u, x_{n}\right)+\left(1-\alpha_{n}\right) D_{f}\left(u, T x_{n}\right)-D_{f}\left(u, x_{n}\right) \\
=\left(1-\alpha_{n}\right)\left(D_{f}\left(u, T x_{n}\right)-D_{f}\left(u, x_{n}\right)\right) .
\end{aligned}
$$

This together with (46), (16), and $\lim _{n \rightarrow \infty} \alpha_{n}<1$ shows that

$$
\lim _{k \rightarrow \infty}\left(D_{f}\left(u, T x_{n}\right)-D_{f}\left(u, x_{n}\right)\right)=0 \text {. }
$$

Since $T$ is Bregman strongly nonexpansive, it follows from (48) that

$$
\lim _{n \rightarrow \infty}\left\|x_{n}-T x_{n}\right\|=0
$$

(V) Next, we prove that every weak subsequential limit of $\left\{x_{n}\right\}$ belongs to $G=F(T) \cap \operatorname{EP}(g)$. 
Since $\left\{x_{n}\right\}$ is bounded, there exists a subsequence $\left\{x_{n_{k}}\right\}$ of $\left\{x_{n}\right\}$ such that $x_{n_{k}} \rightarrow x^{*}$. Since $T$ is a Bregman strongly nonexpansive mapping with $F(T)=\widehat{F}(T)$, we have $x^{*} \in F(T)$.

From $x_{n_{k}} \rightarrow x^{*}$ and (34), we have $u_{n_{k}} \rightarrow x^{*}$.

By $u_{n}=\operatorname{Res}_{g}^{f} y_{n}$, we have

$g\left(u_{n}, y\right)+\left\langle\nabla f\left(u_{n}\right)-\nabla f\left(y_{n}\right), y-u_{n}\right\rangle \geq 0, \quad \forall y \in C$.

Replacing $n$ by $n_{k}$, we have from $\left(A_{2}\right)$ that

$$
\begin{array}{r}
\left\langle\nabla f\left(u_{n_{k}}\right)-\nabla f\left(y_{n_{k}}\right), y-u_{n_{k}}\right\rangle \geq-g\left(u_{n_{k}}, y\right) \geq g\left(y, u_{n_{k}}\right), \\
\forall y \in C .
\end{array}
$$

Since $g(x, \cdot)$ is convex and lower semicontinuous, it is also weakly lower semicontinuous. So, letting $k \rightarrow \infty$, we have from (35), (43), and $\left(A_{4}\right)$ that

$$
g\left(y, x^{*}\right) \leq 0, \quad \forall y \in C .
$$

For $t \in(0,1]$ and $y \in C$, letting $y_{t}=t y+(1-t) x^{*}$, there are $y_{t} \in C$ and $g\left(y_{t}, x^{*}\right) \leq 0$. By condition $\left(A_{1}\right)$ and $\left(A_{4}\right)$, we have

$$
0=g\left(y_{t}, y_{t}\right) \leq \operatorname{tg}\left(y_{t}, y\right)+(1-t) g\left(y_{t}, x^{*}\right) \leq \operatorname{tg}\left(y_{t}, y\right) .
$$

Dividing both sides of the above equation by $t$, we have $g\left(y_{t}, y\right) \geq 0$, for all $y \in C$. Letting $t \downarrow 0$, from condition $\left(A_{3}\right)$, we have

$$
g\left(x^{*}, y\right) \geq 0, \quad \forall y \in C .
$$

Therefore, $x^{*} \in \operatorname{EP}(g)$.

$(\mathrm{VI})$ Now, we prove $x_{n} \rightarrow P_{F(T) \cap \mathrm{EP}(g)}^{f} x$.

Let $w=P_{F(T) \cap E P(g)}^{f} x$. From $w \in F(T) \cap \operatorname{EP}(g) \subset C_{n+1}$, we have $D_{f}\left(x_{n+1}, x\right) \leq D_{f}(w, x)$. Therefore, Lemma 8 implies that $\left\{x_{n}\right\}$ converges strongly to $w=P_{F(T) \cap \mathrm{EP}(g)}^{f} x$, as claimed. This completes the proof of Theorem 12 .

Corollary 13. Let $C$ be a nonempty, closed, and convex subset of a real reflexive Banach space $E$ and $f: E \rightarrow$ $\mathbb{R}$ a strongly coercive Legendre function which is bounded, uniformly Fréchet differentiable, and totally convex on bounded subsets of E. Let $g$ be a bifunction from $C \times C$ to $\mathbb{R}$ satisfying $\left(A_{1}\right)-\left(A_{4}\right)$. Let $\left\{x_{n}\right\}$ be a sequence generated by $x_{0}=x \in$ $C, C_{0}=C$, and

$$
\begin{array}{r}
u_{n} \in C \text { such that } \\
g\left(u_{n}, y\right)+\left\langle\nabla f\left(u_{n}\right)-\nabla f\left(x_{n}\right), y-u_{n}\right\rangle \geq 0, \\
\forall y \in C, \\
C_{n+1}=\left\{z \in C_{n}: D_{f}\left(z, u_{n}\right) \leq D_{f}\left(z, x_{n}\right)\right\}, \\
x_{n+1}=P_{C_{n+1}}^{f} x
\end{array}
$$

for every $n \in \mathbb{N} \cup\{0\}$. Then, $\left\{x_{n}\right\}$ converges strongly to $P_{E P(g)}^{f} x$, where $P_{E P(g)}^{f}$ is the Bregman projection of $E$ onto $E P(g)$.
Proof. Putting $T=I$ in Theorem 12, we obtain Corollary 13.

Corollary 14. Let $C$ be a nonempty, closed, and convex subset of a real reflexive Banach space $E$ and $f: E \rightarrow$ $\mathbb{R}$ a strongly coercive Legendre function which is bounded, uniformly Fréchet differentiable, and totally convex on bounded subsets of E. let $T$ be a Bregman strongly nonexpansive mapping from $C$ into itself such that $F(T)=\widehat{F}(T)$ and $G=F(T) \cap$ $E P(g) \neq \emptyset$. Let $\left\{x_{n}\right\}$ be a sequence generated by $x_{0}=x \in$ $C, C_{0}=C$, and

$$
\begin{aligned}
u_{n} & =P_{C}^{f} \nabla f^{*}\left(\alpha_{n} \nabla f\left(x_{n}\right)+\left(1-\alpha_{n}\right) \nabla f\left(T x_{n}\right)\right), \\
C_{n+1} & =\left\{z \in C_{n}: D_{f}\left(z, u_{n}\right) \leq D_{f}\left(z, x_{n}\right)\right\} \\
x_{n+1} & =P_{C_{n+1}}^{f} x
\end{aligned}
$$

for every $n \in \mathbb{N} \cup\{0\}$, where $\left\{\alpha_{n}\right\} \quad \subset \quad[0,1]$ satisfies $\liminf _{n \rightarrow \infty}\left(1-\alpha_{n}\right)>0$. Then, $\left\{x_{n}\right\}$ converges strongly to $P_{F(T)}^{f} x$, where $P_{F(T)}^{f}$ is the Bregman projection of $E$ onto $F(T)$.

Proof. Putting $g(x, y)=0$ for all $x, y \in C$ in Theorem 12, we obtain Corollary 14.

\section{Acknowledgments}

This work was supported by Scientific Research Fund of Sichuan Provincial Education Department (11ZB146) and Yunnan University of Finance and Economics.

\section{References}

[1] E. Blum and W. Oettli, "From optimization and variational inequalities to equilibrium problems," The Mathematics Student, vol. 63, no. 1-4, pp. 123-145, 1994.

[2] P. L. Combettes and S. A. Hirstoaga, "Equilibrium programming in Hilbert spaces," Journal of Nonlinear and Convex Analysis, vol. 6, no. 1, pp. 117-136, 2005.

[3] A. Moudafi, "Second-order differential proximal methods for equilibrium problems," Journal of Inequalities in Pure and Applied Mathematics, vol. 4, no. 1, article 18, 7 pages, 2003.

[4] A. Tada and W. Takahashi, "Strong convergence theorem for an equilibrium problem and a nonexpansive mapping," in Nonlinear Analysis and Convex Analysis, A. Tada and W. Takahashi, Eds., pp. 609-617, Yokohama Publishers, Yokohama, Japan, 2007.

[5] W. Takahashi and K. Zembayashi, "Strong and weak convergence theorems for equilibrium problems and relatively nonexpansive mappings in Banach spaces," Nonlinear Analysis: Theory, Methods \& Applications, vol. 70, no. 1, pp. 45-57, 2009.

[6] S. Takahashi and W. Takahashi, "Viscosity approximation methods for equilibrium problems and fixed point problems in Hilbert spaces," Journal of Mathematical Analysis and Applications, vol. 331, no. 1, pp. 506-515, 2003.

[7] K. Nakajo and W. Takahashi, "Strong convergence theorems for nonexpansive mappings and nonexpansive semigroups," Journal of Mathematical Analysis and Applications, vol. 279, no. 2, pp. 372-379, 2003. 
[8] W. Takahashi, Y. Takeuchi, and R. Kubota, "Strong convergence theorems by hybrid methods for families of nonexpansive mappings in Hilbert spaces," Journal of Mathematical Analysis and Applications, vol. 341, no. 1, pp. 276-286, 2008.

[9] J.-B. Hiriart-Urruty and C. Lemaréchal, Convex Analysis and Minimization Algorithms II, vol. 306 of Grundlehren der Mathematischen Wissenschaften, Springer, 1993.

[10] C. Zălinescu, Convex Analysis in General Vector Spaces, World Scientific, River Edge, NJ, USA, 2002.

[11] E. Asplund and R. T. Rockafellar, "Gradients of convex functions," Transactions of the American Mathematical Society, vol. 139, pp. 443-467, 1969.

[12] J. F. Bonnans and A. Shapiro, Perturbation Analysis of Optimization Problems, Springer, New York, NY, USA, 2000.

[13] S. Reich and S. Sabach, "A strong convergence theorem for a proximal-type algorithm in reflexive Banach spaces," Journal of Nonlinear and Convex Analysis, vol. 10, no. 3, pp. 471-485, 2009.

[14] H. H. Bauschke, J. M. Borwein, and P. L. Combettes, "Essential smoothness, essential strict convexity, and Legendre functions in Banach spaces," Communications in Contemporary Mathematics, vol. 3, no. 4, pp. 615-647, 2001.

[15] H. H. Bauschke and J. M. Borwein, "Legendre functions and the method of random Bregman projections," Journal of Convex Analysis, vol. 4, no. 1, pp. 27-67, 1997.

[16] Y. Censor and A. Lent, "An iterative row-action method for interval convex programming," Journal of Optimization Theory and Applications, vol. 34, no. 3, pp. 321-353, 1981.

[17] L. M. Brègman, "The relaxation method of finding a common point of convex sets and its application to the solution of problems in convex programming," USSR Computational Mathematics and Mathematical Physics, vol. 7, no. 3, pp. 200217, 1967.

[18] D. Butnariu and E. Resmerita, "Bregman distances, totally convex functions, and a method for solving operator equations in Banach spaces," Abstract and Applied Analysis, vol. 2006, Article ID 84919, 39 pages, 2006.

[19] E. Resmerita, "On total convexity, Bregman projections and stability in Banach spaces," Journal of Convex Analysis, vol. 11, no. 1, pp. 1-16, 2004.

[20] D. Butnariu and A. N. Iusem, Totally Convex Functions for Fixed Points Computation and Infinite Dimensional Optimization, Kluwer Academic Publishers, Dordrecht, The Netherlands, 2000.

[21] S. Reich and S. Sabach, "Two strong convergence theorems for a proximal method in reflexive Banach spaces," Numerical Functional Analysis and Optimization, vol. 31, no. 1-3, pp. 2244, 2010.

[22] Y. Censor and S. Reich, "Iterations of paracontractions and firmly nonexpansive operators with applications to feasibility and optimization," Optimization, vol. 37, no. 4, pp. 323-339, 1996.

[23] S. Reich, "A weak convergence theorem for the alternating method with Bregman distances," in Theory and applications of Nonlinear Operators of Accretive and Monotone Type, pp. 313318, Marcel Dekker, New York, NY, USA, 1996.

[24] S. Reich and S. Sabach, "Two strong convergence theorems for Bregman strongly nonexpansive operators in reflexive Banach spaces," Nonlinear Analysis: Theory, Methods \& Applications, vol. 73, no. 1, pp. 122-135, 2010.

[25] R. E. Bruck and S. Reich, "Nonexpansive projections and resolvents of accretive operators in Banach spaces," Houston Journal of Mathematics, vol. 3, no. 4, pp. 459-470, 1977.
[26] S. Reich and S. Sabach, "Existence and approximation of fixed points of Bregman firmly nonexpansive mappings in reflexive Banach spaces," in Fixed-Point Algorithms for Inverse Problems in Science and Engineering, pp. 301-316, Springer, New York, NY, USA, 2011.

[27] R. P. Phelps, Convex Functions, Monotone Operators, and Differentiability, vol. 1364 of Lecture Notes in Mathematics, Springer, Berlin, Germany, 2nd edition, 1993.

[28] E. Blum and W. Oettli, "From optimization and variational inequalities to equilibrium problems," The Mathematics Student, vol. 63, no. 1-4, pp. 123-145, 1994.

[29] P. L. Combettes and S. A. Hirstoaga, "Equilibrium programming in Hilbert spaces," Journal of Nonlinear and Convex Analysis, vol. 6, no. 1, pp. 117-136, 2005.

[30] A. Ambrosetti and G. Prodi, A Primer of Nonlinear Analysis, Cambridge University Press, Cambridge, UK, 1993. 


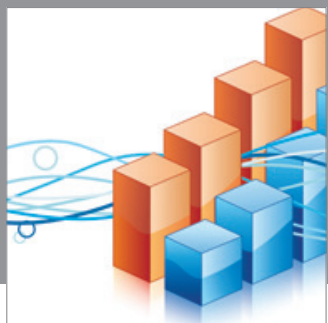

Advances in

Operations Research

mansans

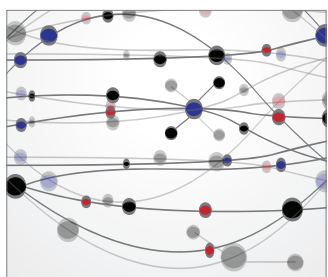

The Scientific World Journal
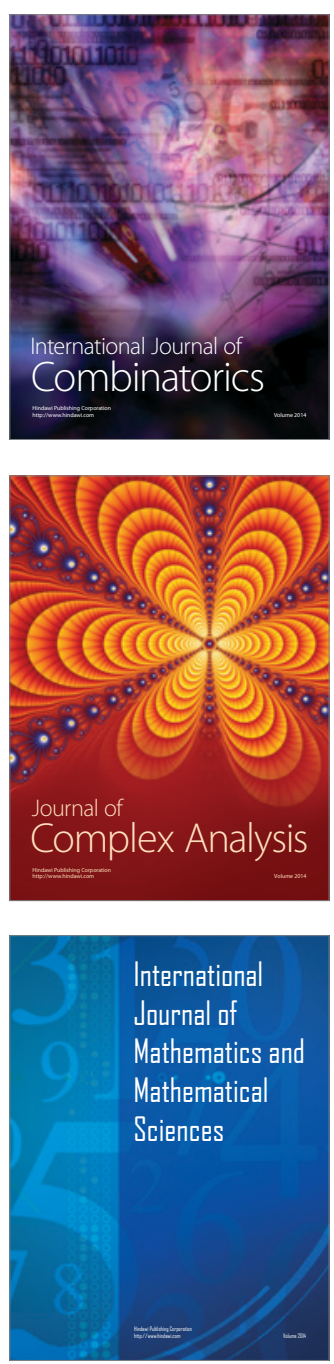
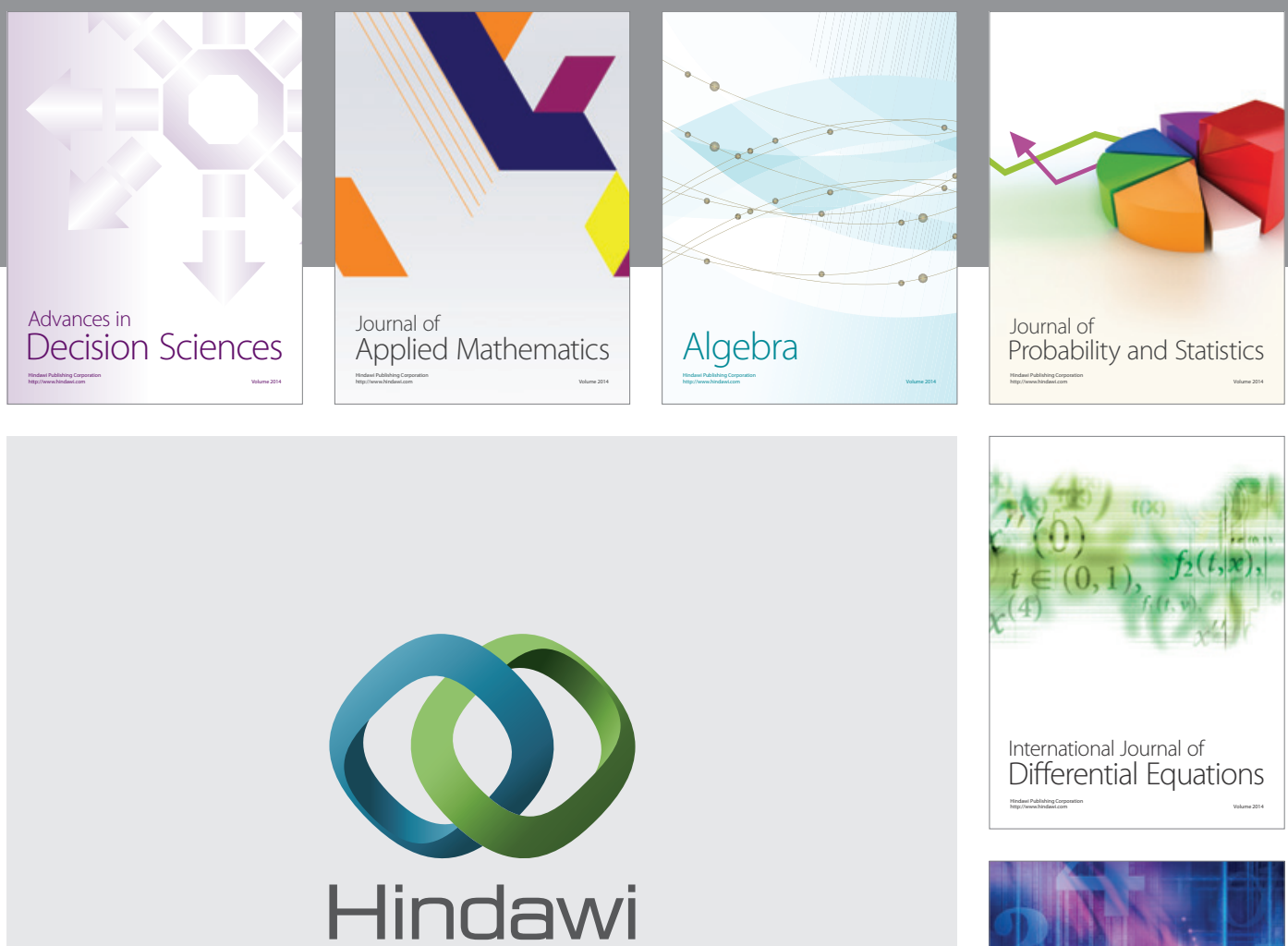

Submit your manuscripts at http://www.hindawi.com
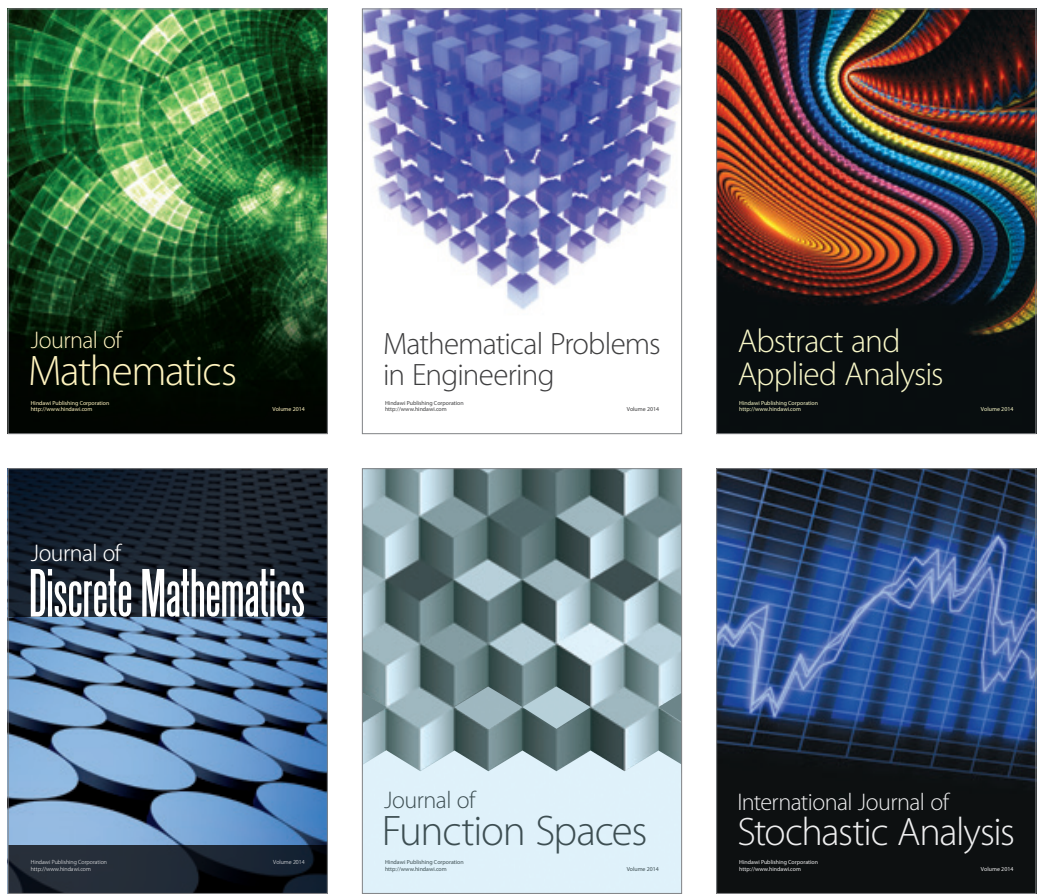

Journal of

Function Spaces

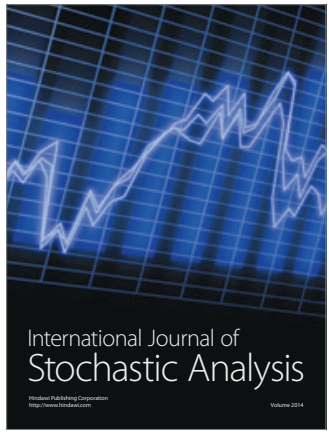

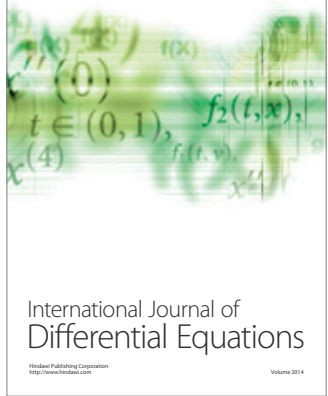
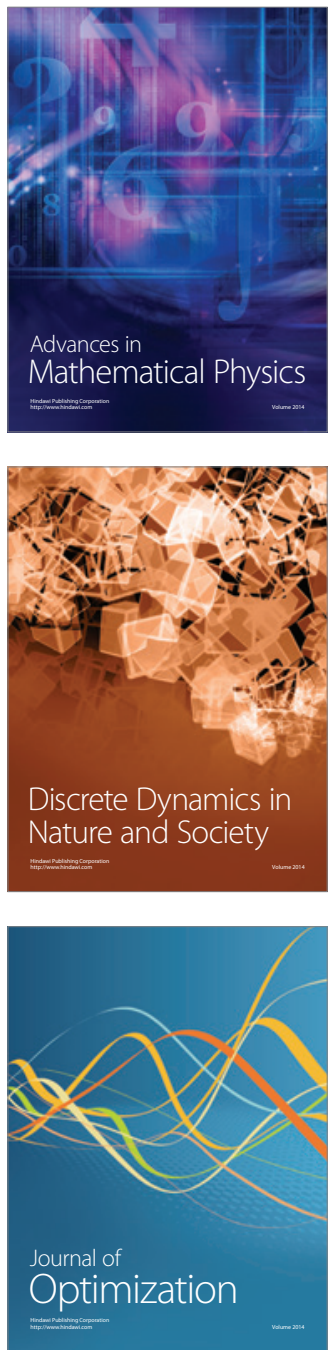